\title{
Prevotella bivia
}

National Cancer Institute

\section{Source}

National Cancer Institute. Prevotella bivia. NCI Thesaurus. Code C86661.

A species of obligately anaerobic, Gram-negative, rod shaped bacteria assigned to the phylum Bacteroidetes. This species is non-motile, non-spore forming, produces succinic and acetic acid from peptone-yeast-glucose medium, non-pigmented, indole negative, hydrolyzes starch, but not esculin, digests gelatin, milk, casein and meat, and ferments glucose, maltose, starch, lactose, galactose, and mannose, but not sucrose. P. bivia has been isolated from the oral cavity and the female genital tract and is associated with abscesses and a variety of systemic infections. 